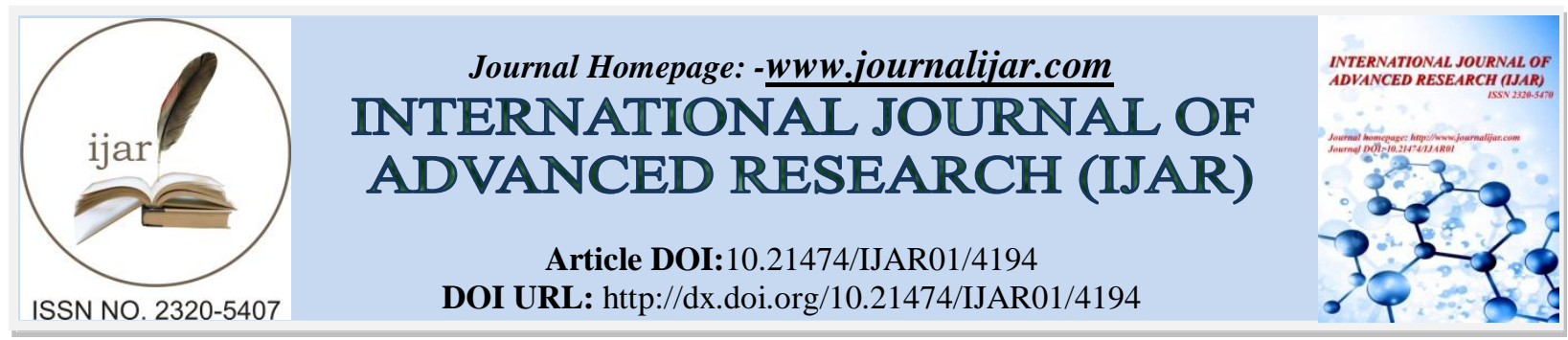

CASE REPORT

\title{
FIBER REINFORCED COMPOSITE MATERIAL AS A TREATMENT MODE FOR AESTHETIC REPLACEMENT OF MISSING TEETHWITH STABILIZATION OF PERIODONTALLYMOBILED TEETH - A CASE REPORT.
}

\begin{abstract}
Manvendra Singh Sengar, Sudhir S Patil, PoorvaBain and Ashish Nema.
Department of Periodontology, Maharana Pratap College of Dentistry \& Research Centre, Gwalior (M.P)-474006, India.
\end{abstract}

\section{Manuscript Info}

Manuscript History

Received: 14 March 2017

Final Accepted: 19 April 2017

Published: May 2017

\section{Keywords:-}

Missing tooth, Replacement, Fiber reinforced composite splint,

Periodontitis.

\section{Abstract}

Periodontal disease can lead to severe tooth mobility so often patient complains of pain while eating, decreased chewing ability and functional occlusion. Missing anterior teeth is of serious concern in the social life of a patient in most of the societies. Replacement of missing anterior teeth due to periodontal reasons is challenging due to the poor support of abutment teeth. This prevents the use of fixed partial dentures(FPDs).Fiber reinforce composite (FRC) resins offer a conservative, fast, and cost-effective alternative for single and multiple teeth replacement and may prove to be a successful modality for aesthetic and functional replacement of missing teeth along with periodontally compromised abutments, which has always been a challenge for the dentist. This case report describes treatment of chronic periodontitis patients with splinting fiber composites as a method for stabilization of the lower anterior teeth providing aesthetics by replacing the missing teeth.

Copy Right, IJAR, 2017,. All rights reserved.

\section{Introduction:-}

The periodontally weakened teeth often drift to apposition that is esthetically unpleasant as well as functionally unstable. The altered forces acting on teeth worsen the migration. Many of these patients want the correction of diastema and an esthetically pleasant look but are not ready to sacrifice the periodontally hopeless teeth. The ultimate goal of successful management of mobile teeth is to restore function and comfort by establishing a stable occlusion that promotes tooth retention and the maintenance of periodontal health. ${ }^{1}$

Tooth mobility is a common problem on the teeth due to gingiva and bone support disease or injury, furthermore give raise to tooth loss. Tooth mobility may be a physiological or pathological condition. The increased mobility can be caused by many factors. But the inflammation by the accumulation of plaque and trauma due to occlusion were most often factors implicated as the cause of tooth mobility.

Typically, a splint is indicated due to a single tooth or multiple teeth having mobility. However, the reasons to stabilize periodontally compromised teeth include decreased patient discomfort, increased occlusal and masticatory function, and improved prognosis of mobile teeth. ${ }^{2,3}$ 
Different materials have been successfully used for splinting which include-composite, wire and composite and fiber reinforced splints. In order to fulfill both the periodontal and restorative needs, ribbons and fibers were developed that could be reinforced with composite resin to form thin-but-strong splints.

The advantages of fiber reinforced composite material for periodontal splinting include:

a. Ease of application with minimal tooth preparation.

b. Low to moderate cost as compared to fixed prostheses.

c. Can easily be removed when splinting is no longer considered necessary.

d. Easily repaired in case of failure through re-bonding and re-application of material.

e. Ease of accommodation of oral hygiene practices by the patient. ${ }^{4}$

When replacing missing anterior teeth, thorough treatment planning is essential. Correct choice of materials and bonding techniques are important factors to fulfill the need for durable restoration without compromising aesthetics of FRC-fixed partial denture. The FRC prosthesis fabricated using two approaches, the firstapproach is based on conventional tooth preparation and laboratory made restoration, second approach is based on using fibers in minimally invasive restoration by direct or indirect fabrication. ${ }^{5}$

This case report describes the splinting of periodontally compromised mandibular anteriors with fiber reinforced composite material and replacing the missing teeth.

\section{Case Report:-}

A 24 year old lady reported to the department ofPeriodontics, Maharana Pratap College of Dentistry\& Research Centre,Gwalior, with the chief complaint of unaesthetic appearance and discomfort during function, associated with the mandibular anterior teeth due to mobility. Patient had lost mandibular right central incisor due to advanced periodontal disease (Figure-1). Clinical and radiographic examination revealed that the patient had maximum intercuspal position, moderate bone loss with Grade I tooth mobility in mandibular anterior teeth.(according to the Miller index for tooth mobility).The teeth were scaled and root-planed to assure that allcalculus and stains were removed.

For replacing the missing teeth an acrylicpontic teeth is to be selected from the set with same shade as of natural teeth which is to be bonded directly with fiber splint. This procedure is an alternative to the removable partial denture, resin retained prosthesis and conventional fixed partial denture to rehabilitate the prosthetic spaceand create a periodontal splint for the abutment teeth.

\section{Procedure:-}

The teeth were cleaned on the facial and lingualsurfaces using a prophylaxis cup with a nonfluoridatedpumice paste. The length of reinforced fiber was determined by placing the dental floss on facial side of the mandibular anterior teeth from distal end of left canine to distal end of right canine (figure-1). After the teeth were thoroughly rinsed and dried, the lingual surface of teeth to be splinted were etched with $37 \%$ phosphoric acid (3M)for 30 seconds. The preparations were rinsed with water and dried. ${ }^{6,7}$

A bonding agent $(3 \mathrm{M})$ was applied on all the prepared abutments and fiber mesh. The excess bonding agent was removed, a thin layer of flowablecomposite was applied to the lingual surface of abutment, and the length of polyethylene fiber mesh was carefully placed on the lingual surface of the abutments just above the cingulum, composite was again applied over the fiber mesh. ${ }^{8,9}$ The restoration werepolymerized for 30 seconds with light polymerizing unit at $420 \mathrm{mw} / \mathrm{cm}^{2}$ from lingual and facial surface of abutment and edentulous space (figure-2).

Acrylicpontic was prepared on to the facial aspect of already cured fiber band in the edentulous space. Additional composite resin was applied to blend the FRC contours and light polymerized (figure-3). Incisaladjustments were accomplished and final finishing and polishing done. 


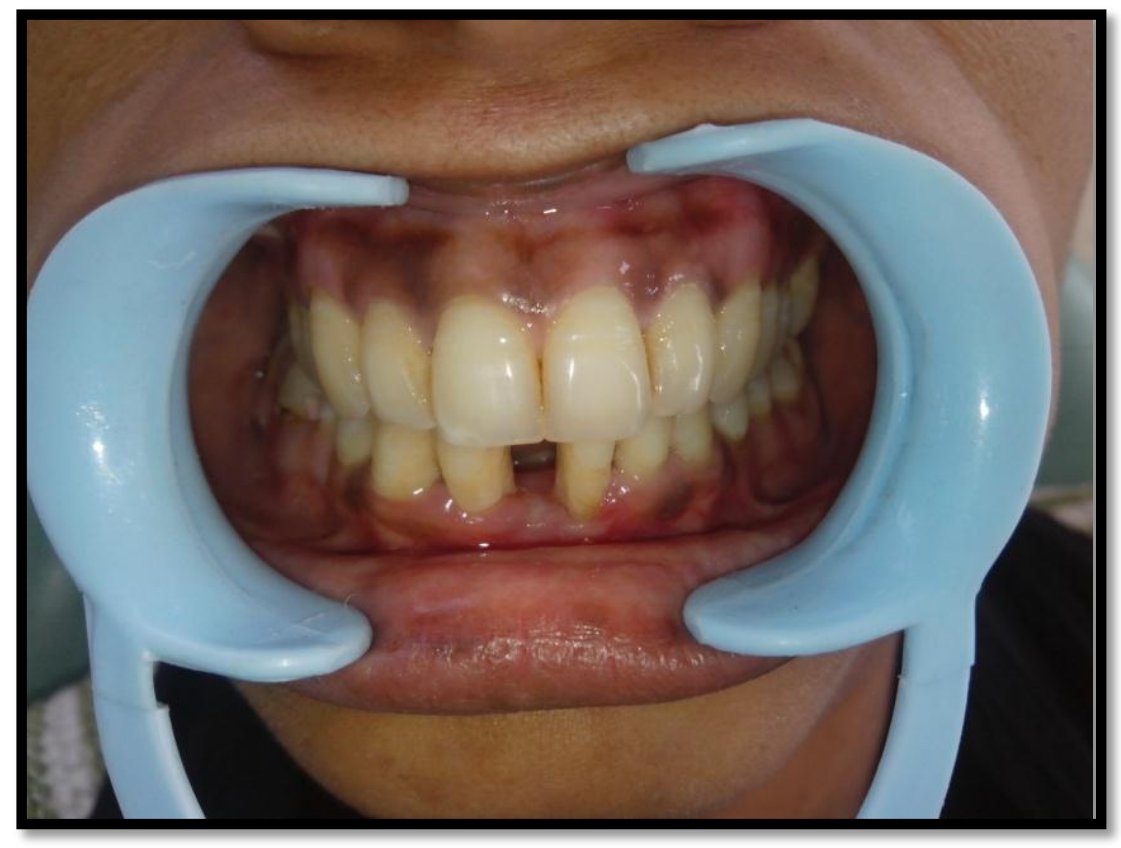

Figure 1:- Preoperative view showing missing right central incisor

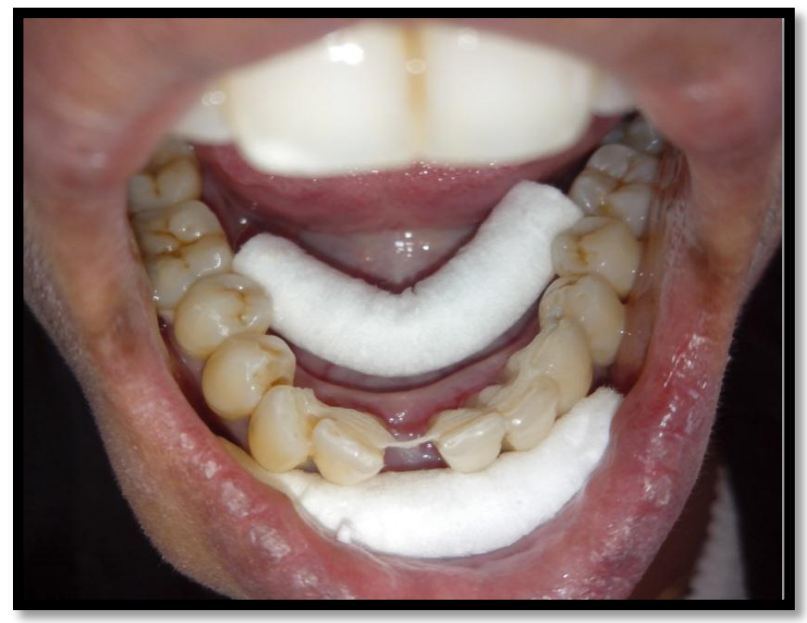

Figure 2:-Showingfiber splint bonded on lingual aspect

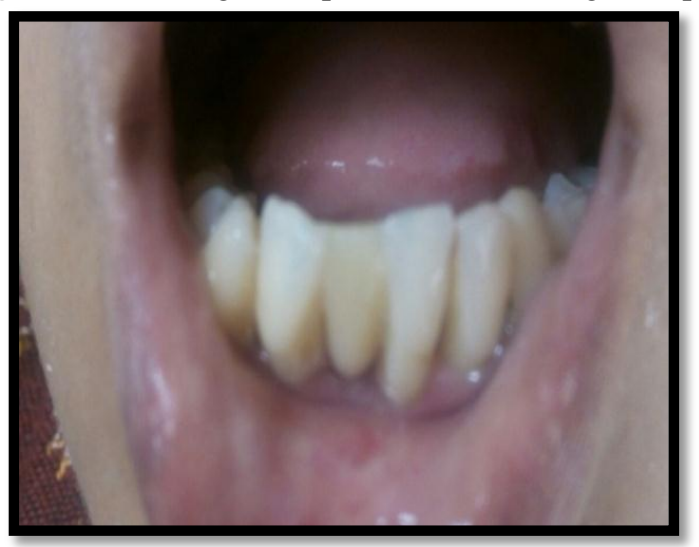

Figure 3:- Postoperative facial view showing rehabilitation of missing tooth with periodontal splint 
Routine oral hygiene instructions were given, the patient was evaluated every 3 months for review and periodontal therapy was observed to be effective in obtaining optimal oral health. Periodontally compromised abutment teeth exhibited signs of periodontal health,patient was highly satisfied with aesthetic and functional outcome of the treatment.

\section{Discussion:-}

This clinical report describes the aesthetic replacement of a missing mandibular right central incisor and splinting of periodontally compromised teeth adjacent to the prosthetic space with a conservative FRC-FPD resulting in success over a short-term follow up. This treatment option can be categorized as a periodontalprosthesis. Direct technique is conservative, cost effective, eliminates laboratory procedure. The prosthesis can be placed in a single visit using natural teeth, acrylic tooth or composite resin teeth as a pontic. The aesthetics of the FRC-FPD was shown to be considerably better than the aesthetics of FPDs with metal frameworks, as subjectively determined by many observers. ${ }^{10,11}$

It must be emphasized to the patient to avoid heavy biting pressure on the splinted teeth. All eccentric movements should be recorded and relieved. Long-term follow-up is essential to evaluate the fiber reinforced resin splint as an alternative to the conventional partial denture or the fixed prostheses.

\section{Conclusion:-}

Tooth stabilization using the innovative techniques incorporating bonded reinforcing materials for anterior periodontal tooth stabilization abides by the conservation of natural tooth structure, provides good fracture resistance with unparalleled esthetic value. This case report describes the clinicalprocedure using conservative, aesthetic and cost effective FRC-fixed partial denture which splint the periodontally compromised teeth.

\section{References:-}

1. Tarnow DP, Fletcher P. Splinting of periodontally involved teeth: indications and contraindications. NY State Dent J. 1986;52:24-25.

2. Serio FG, Hawley CE. Periodontal trauma and mobility. Diagnosis and treatment planning. Dent Clin North Am. 1999;43:37-44.

3. Waerhaug J. Justification for splinting in periodontal therapy. J Prosthet Dent. 1969;22:201-208.

4. Kini V, Patil SM, Jagtap R. Bonded reinforcing materials for estheticanterior periodontal tooth stabilization: A case report. Int J Dent Clin2011;3:90-1.

5. Chauhan M. Natural tooth pontic fixed partial denture using resin composite reinforced glass fibers. Quintessence Int2004;35:549-53.

6. Klassman B, Zucker HW. Combination wire composite intercoronal splinting rationale and technique. J Periodontal 1976;47:481-486.

7. Schmid MO, Lutz F, Imfeld T. A new reinforcedintracoronal composite resin splint. Clinical result after 1 year. J Periodontal 1979; 50:441-444.

8. Miller TE. A new material for periodontal splinting and orthodontic retention. CompendContinEduc Dent 1993; $14: 800-812$.

9. Miller TE, Hakimzadeh F, Rudo DN. Immediate and indirect woven polyethylene ribbon reinforced periodontal -prosthetic splint: A case report. Quintessence Int 1995; 26:267-271.

10. Vallittu PK, Sevelius C. Resin bonded, glass fiber reinforced composite fixed partial dentures: Aclinical study. J Prosthet Dent 2000; 84:413-8.

11. Rudo DN, Karbhari VM. Physical behaviors of fiber reinforcement as applied to tooth stabilization. Dent Clin North Am 1999; 43:7-35. 